\title{
DISCRIMINAÇÃO DA MULHER NO MERCADO TRABALHO: DESTACANDO A MULHER NEGRA NESTE PROCESSO
}

\author{
Eloy Pereira Lemos Junior* \\ Carolina Silva**
}

\begin{abstract}
Resumo
$\mathrm{O}$ artigo tem como objetivo analisar a discriminação da mulher no mercado de trabalho, destacando a mulher negra na participação deste processo. Mostrando a importância da discussão sobre a desigualdade entre o homem e a mulher no ambiente profissional, para que haja uma legítima e necessária mudança que alcance dentro das relações de trabalho a igualdade entre os gêneros, raças e salários. Tudo isso refletindo sobre a implementação dos direitos fundamentais nas relações sociais. Para o desenvolvimento do trabalho utilizou-se o método de pesquisa dedutivo-hipotético, através de exposição de posicionamentos doutrinários e jurisprudenciais.
\end{abstract}

Palavras-chave: Direitos Fundamentais. Relações de Trabalho. Discriminação. Mulher Negra. Gênero.

\section{WOMAN DISCRIMINATION IN THE LABOR MARKET: HIGHLIGHTING THE BLACK WOMAN IN THIS PROCESS}

\begin{abstract}
The article aims to analyze the discrimination of women in the labor market, highlighting black women in the participation of this process. Showing the importance of the discussion about the inequality between men and women in the professional environment, so that there is a legitimate and necessary change that achieves gender equality, races and wages within working relationships. All this reflecting on the implementation of fundamental rights in social relations. For the development of the work the deductive-hypothetical research method was used, through the exposition of doctrinal and jurisprudential positions.
\end{abstract}

Keywords: Fundamental rights. Work relationships. Discrimination. Black women. Gender.

\section{INTRODUÇÃO}

Ao longo dos anos a mulher tem batalhado para ser reconhecida e valorizada como parte fundamental e necessária no mercado de trabalho. E mesmo atingindo um alto grau de conhecimento e chegando a um elevado nível de educação e profissionalização, a mulher

\footnotetext{
* Doutor em Direito pela UFMG com pós-doutorado em Direito Empresarial (Puc-MG) e Administração de Empresas (Fumec). Mestre. Especialista pela Universidade de Lisboa. Avaliador INEP/MEC. Professor de pósgraduação e graduação. Autor e avaliador de artigos qualificados CAPES. Pesquisador e advogado. eloy.junior@uol.com.br.

** Pós-graduação em Direito do Trabalho e Previdenciário no Centro Universitário Una. Graduada em Direito pela Fundação Universidade de Itaúna, FUIT. carolina.silva08@hotmail.com.
} 
ainda encontra vestígios de discriminação e desigualdade por parte da sociedade atual, que tanto debate sobre a igualdade de gêneros e etnias.

O que se presencia em nosso dia a dia é bem diferente do que o disposto pela própria Constituição Federal, que discursa em um de seus artigos sobre o direito de todos os indivíduos em terem uma vida digna, prevalecendo à igualdade independente de qualquer natureza.

O problema enfrentado no estudo em questão é analisar a discriminação e o racismo enfrentados no mercado de trabalho, pelas mulheres brancas, e mais ainda pelas negras. Justifica-se a importância do estudo e conscientização do presente tema para combater a desigualdade entre os sexos que é uma realidade contemporânea na sociedade. Tudo isso tendo como foco a reflexão sobre a implementação dos direitos fundamentais nas relações sociais.

Será iniciado o estudo em seu primeiro capítulo, abordando de forma geral o direito do trabalho para a mulher, trazendo como base, antecedentes históricos e atuais da diferenciação dos gêneros no ambiente de trabalho, contando também com as leis regulamentadoras e uma análise nas diferenças entre cargos e salários.

Em um segundo momento será apontado o tema discriminação, trazendo ainda noções sobre a desigualdade e a discriminação de gêneros e raça, no ambiente de trabalho.

Seguindo em seu terceiro capítulo, será trabalhada a questão dos princípios protetores da mulher dentro do direito trabalhista, bem como o princípio constitucional da igualdade e suas vertentes e o princípio da não discriminação da mulher.

Pretende-se com o presente trabalho, através de pesquisas de natureza exploratória, descritiva e explicativa, demonstrar a discriminação da mulher e a realidade da mulher negra em meio às desigualdades sociais dentro do mercado de trabalho, com base no contexto apresentado para a compreensão do momento em que vive a mulher perante o Direito do Trabalho, evidenciando por meio de analises a diferenciação e a ascensão a cargos e salários entre o homem e a mulher.

Para o desenvolvimento do trabalho utilizou-se o método de pesquisa dedutivohipotético, através de exposição de posicionamentos doutrinários e jurisprudenciais.

\section{A MULHER E O DIREITO AO TRABALHO}


Desde os tempos remotos, a mulher ocupa papel inferior em relação ao homem. Inseridas em uma sociedade patriarcal, em que deviam obediência a seus maridos, eram tidas como instrumentos, que deveriam cuidar das tarefas domésticas, de seus filhos e dos maridos, os quais se consideravam seus donos.

Rousseau, filósofo e teórico do iluminismo, compreendia a mulher como sendo um ser idealizado para agradar o homem, desacreditando na ideia de que homens e mulheres podem viver com direitos iguais e livremente, como podemos ver:

[...] As mulheres são naturalmente mais fracas, apropriadas para a reprodução, mas não para a vida pública. As mulheres devem ser educadas para agradar os homens e serem mães. Devem ser educadas na reclusão sexual e castidade que legitimam a paternidade. Na família os homens devem governar essas frívolas criaturas. Devem aprender a estimular o desejo masculino e ao mesmo tempo impedir a lascívia dos homens. A sedução é própria de sua natureza; elas são desejosas de agradar, modestas, tolerantes da injustiça, ardilosas, vãs e artistas em grau menor (ROUSSEAU apud NYE, 1995, p.20).

Desse modo, podemos perceber que em tempos passados, tanto as mulheres brancas quanto as mulheres negras, eram tratadas como um objeto, o que diferem ambas é que ao contrário das mulheres brancas que eram "criadas" para constituir família, as mulheres negras eram criadas para trabalhos domésticos e satisfação sexual, sendo exploradas física e psicologicamente. Mais ainda, as mulheres brancas somente poderiam ter voz ativa em seu lar desde que tivessem algum poder aquisitivo, já as mulheres pobres, a única saída que lhes restava era trabalhar para fornecer o sustento à família, enfrentando os preconceitos.

Deu-se no século XVIII, a Revolução Industrial que trouxe desenvolvimento e oportunidade para que as mulheres pudessem ingressar também no mercado de trabalho.

Tal processo acarretou uma mudança na sociedade, que ocasionou uma transformação no que até então já estava determinado para as mulheres, que era somente o trabalho do lar. Mas essa mudança trouxe, além de desenvolvimento, algumas implicações como: salários baixos, longas jornadas de trabalho e duplas jornadas, conciliando o trabalho doméstico com o trabalho fora do lar e condições inadequadas e abusivas de serviço. $\mathrm{O}$ trabalho da mulher continuou sendo desvalorizado, era tido como inferior ou de menor valor ao do masculino. No entanto, devido a condições de desemprego e miséria que abatiam a época, para prover o seu sustendo e em muito dos casos de suas famílias, se sujeitavam a essas circunstâncias para sobreviverem. 
Assim, com a chegada do desenvolvimento econômico e do comércio, a mulher se viu requisitada para o trabalho fora do lar, visto que para os empregadores da época teriam grande serventia, de maneira especial nos períodos das duas grandes guerras mundiais em que os homens eram necessários para defender seus países, ausentando-se de seus lares e dos empregos, com isso deixando as mulheres responsáveis pelo cuidado do lar e do provimento de recursos para sustento de suas famílias, adquirindo aos poucos mais independência.

De acordo com a escritora, Mirla Cisne, a diferença existente no mercado de trabalho, é como se fosse uma divisão sexual do trabalho, de modo que a mulher fica abaixo do homem na hierarquia, o que já é algo construído desde o início dos tempos, que é uma forma da exploração de capital, obrigando as mulheres a trabalharem em ambientes precários e não tendo seu valor reconhecido. De acordo com Cisne (2015, p. 45):

A não valorização do trabalho faz com muitas mulheres não se percebam como
trabalhadoras, não construindo, portanto, a identidade com sua classe. Isso faz com
que algumas mulheres se acomodem, não se organizem e nem participem
politicamente das lutas da classe trabalhadora.

Isto posto, tem-se que devido aos antecedentes históricos e os paradigmas construídos ao longo dos séculos, criou-se mulheres em sua maioria que se acostumaram com o pouco que lhes foi dado, e o quão é importante e necessário a luta da classe feminina para conquistar seu espaço na sociedade, seu reconhecimento e sua valorização.

\subsection{Atual situação das mulheres no ambiente laboral}

Apesar de já ter conquistado grandes avanços na luta por seus direitos, a mulher ainda tem um longo caminho a percorrer para que tenha seus direitos igualados e exercidos como os dos homens.

Mesmo sendo maioria na população brasileira (98,419 milhões de homens 48,4\% do total e 104,772 milhões de mulheres 51,6\%, segundo pesquisa da PNAD Contínua - IBGE, 2018), as mulheres têm menos espaço no ambiente laboral, e uma maior participação no trabalho não remunerado do lar.

Muitas mulheres possuem dupla jornada, conciliando o trabalho do lar, que envolve cuidados com os filhos, casa, marido, em alguns casos os estudos, com o trabalho fora do lar, podendo-se afirmar que: 
[...] o combate à opressão contra a mulher se torna mais acentuado, onde era preciso mais do que nunca lutar pela sua emancipação econômica e social, pelo seu direito ao trabalho, com todas as especificidades que isso implica, como por exemplo, salários iguais para trabalhos iguais, além da reivindicação de uma divisão mais justa no trabalho doméstico, na esfera reprodutiva, libertando, ao menos parcialmente, a mulher da dupla jornada. (NOGUEIRA, 2010, p. 59).

Os afazeres domésticos, continuam sendo uma função atribuída às mulheres, ainda as que trabalham fora em busca do sustento do lar, em sua maioria se vêm na obrigação de cumprir com esse papel, visto que ainda existe grande preconceito por parte da sociedade masculina e até feminina em relação à contribuição dos homens nessa tarefa.

[...] o emprego e o trabalho feminino remunerado crescem, mas, mesmo ampliando a participação feminina no mundo produtivo as tarefas domésticas continuavam reservadas exclusivamente à mulher, ou seja, a organização da família patriarcal pouco é alterada, o marido se mantém provedor e a esposa a provedora complementar e dona de casa, confirmando a divisão sexual desigual do trabalho. (NOGUEIRA, 2010, p. 59).

O trabalho sem remuneração da mulher, que é exercido no dia a dia em seus lares, não é contabilizado pelas estatísticas e não possui uma valorização social, ainda que contribuam de forma importante e significativa para a sociedade.

Buscando aperfeiçoar e melhorar seu currículo para mais reconhecimento no mercado de trabalho, melhores condições de trabalho, respeito, melhores salários, cargos e outros benefícios, a mulher ainda recebe salários mais baixos que o dos homens, e ainda ocupam cargos inferiores e intensivos.

Uma pesquisa realizada pelo site de empregos CATHO, feita com aproximadamente 8 mil profissionais, revela que as mulheres ganham menos que os homens em todas áreas e cargos de atuação pesquisados (até mesmo nas áreas em que há predominância feminina), a diferença salarial chega a quase $53 \%$ (cinquenta e três por cento). O salário dos homens é superior ao das mulheres em todos os níveis de escolaridade pesquisados, conforme gráfico representado abaixo (CATHO, 2018, on line)

Kátia Garcia (CATHO, 2018, on line), gerente de relacionamento com clientes da CATHO, afirma que essa diferença salarial, pode ser esclarecida pelo fato de que as mulheres interrompem sua vida profissional mais vezes que os homens, com a chegada da maternidade ou por trocarem de carreira e terem que começar em outra área do zero com mais frequência do que os homens, e reconhece que levará tempo até que as condições sejam equiparadas. 
No mundo todo, observa-se que os homens trabalham quatro vezes mais como empregadores do que as mulheres no ano de 2018. Essa diferenciação de gênero também pode ser percebida nos cargos de gestão, onde as mulheres permanecem enfrentando obstáculos no mercado de trabalho para chegar nestes setores.

Pesquisas também afirmam que quanto maior o cargo, mais alta será a desigualdade. O cargo de presidente é o que tem a menor quantidade de mulheres com proporção de 22,91\% em 2011, com aumento de 2,94 pontos percentuais, chegando a 25,85 em 2017 (CATHO, 2017, on line). No cargo de encarregado, o mais baixo em nível de gestão, é nele que consta a maior quantidade de mulheres, com 54,99\% no ano de 2011 , e aumento de $61,57 \%$ até o ano de 2017. No entanto, ainda possível vislumbrar um número que poderia ser mais relevante.

\section{DISCRIMINAÇÃO}

A discriminação será sempre um comportamento que diminua ou exclua o outro, sem um motivo real, do processo de participação da sociedade, e é exatamente por esse motivo que deve ser combatida. Cuida de uma diferenciação de tratamento, sem motivos lógicos para tal, com base em algum tipo de preconceito já existente relacionado a alguma característica pessoal, como orientação sexual, gênero, etnia, religião e outras.

Doutrinariamente, podemos afirmar que a discriminação é um ato de negar a uma ou mais pessoas um tratamento adequado ao modelo jurídico determinado para a situação em que se encontra.

O autor Mauricio Godinho Delgado, narra três situações discriminatórias como as mais habituais nos ambientes corporativos, e uma situação considerada atual, como podemos observar:

\footnotetext{
As três situações tradicionais são: aquela envolvente ao instituto da equiparação salarial, as situações similares que ocorram em empresas que organizam seus trabalhadores em quadro de carreira, finalmente, a situação que trata do nível salarial devido ao empregado substituto provisório de um colega que receba salário superior. A situação nova criada no mercado de trabalho e que também suscita o debate acerca do tema da discriminação é aquela envolvente aos trabalhadores submetidos ao mecanismo da terceirização. (DELGADO, 2001, p. 863)
}

A discriminação pode ocorrer em todas as fases do pacto laboral, sendo elas a admissão, durante o contrato e a demissão. Na admissão pode ocorrer por parte dos empregados da empresa que se recusam ou se indispõem em trabalhar com alguém, somente 
por suas características pessoais, ou quando a empresa comete o ato de discriminação por meio de anúncios de emprego que firam a moral e ética social. Já durante o contrato, pode acontecer na incumbência de tarefas inferiores, que não irão resultar em chances de ascensão, ou que não necessitem de qualquer qualificação. No fim do contrato, pode acontecer a discriminação quando ocorrer à demissão por parte do empregador, com a justificativa de que há uma certa necessidade em conter gastos, e então dispensa alguns funcionários, como por exemplo, apenas mulheres e em idade favorável para gestação.

A discriminação pode ser vista na sociedade de forma indireta, direta e oculta. Thereza Cristina Gosdal, dispõe sobre o assunto:

\begin{abstract}
A discriminação pode assumir feições diversas, efetivando-se direta ou indiretamente, ou consolidando-se em ações positivas. A discriminação direta é aquela pela qual o tratamento desigual funda-se em critérios proibidos. É, por exemplo, a não contratação de empregados negros. A discriminação indireta é a que tem uma aparência formal de igualdade, mas que em verdade cria uma situação de desigualdade. É o caso, por exemplo, da instituição de um adicional de remuneração a uma determinada função, ocupada exclusivamente por homens. (2003, p. 94-95)
\end{abstract}

Na discriminação direta, o empregado passa por um tratamento diferente, que podem causar efeitos danosos, baseado em motivos como: sexo, estado civil, raça, idade ou outra característica elencada pela lei. A indireta é aquela que não é tão visível quanto a direta, tem aspecto formal de igualdade, mas que produz efeitos negativos criando a desigualdade. Já a discriminação oculta, será a que não é possível comprovar que a ação do empregador era discriminatória, tornando oculta a situação de discriminação.

Portanto, pode-se qualificar como discriminação toda e qualquer exclusão, diferenciação ou preferência fundada em relação a gênero, raça, cor, nacionalidade, sexualidade ou etnia que tenha como objetivo diminuir o outro.

\title{
3.1 Desigualdade de gênero e raça no mercado de trabalho
}

O mercado de trabalho está marcado pelas alarmantes desigualdades de gênero e cor. Apesar das mulheres terem avançado mais no quesito educacional, continuam em desvantagem em relação aos homens, pois o desenvolvimento das mesmas, não se transformaram em melhores posições de cargos, e nem elevou a já citada, questão salarial.

Estudos apontam que mulheres e negros têm mais dificuldade para serem inseridos de fato no mercado de trabalho e é de responsabilidade do Governo Federal, a criação de 
planos de política e a promoção da não discriminação, possibilitando a criação de oportunidades iguais para todos que desejam adentrar no mercado de trabalho brasileiro.

Quando se refere ao papel da mulher no ambiente laboral, a sociedade apoia o pensamento de que a mulher, apenas pelo fato de ser mulher, deveria exercer certo tipo de função pré-estabelecendo uma "regra social", que gera desigualdades. Lauretis considera (1994):

\begin{abstract}
As concepções culturais de masculino e feminino como duas categorias complementares, mas que se excluem mutuamente, nas quais todos os seres humanos são classificados formam dentro de cada cultura, um sistema de gênero, um sistema simbólico ou um sistema de significações que relaciona o sexo a conteúdos culturais de acordo com valores e hierarquias sociais. Embora os significados possam variar de uma cultura para outra qualquer sistema de sexogênero está sempre intimamente interligado a fatores políticos e econômicos em cada sociedade (LAURETIS, 1994, p. 211)
\end{abstract}

O lugar em que o ser humano vive influenciará na construção de seus valores, sejam indivíduos do sexo masculino ou feminino, valores estes que envolvem fatores sociais, culturais, políticos e econômicos, e que serão reproduzidos nos ambientes sociais.

Quando se fala da participação da população negra no ambiente de trabalho, vem à tona a imagem que nos faz entender as desigualdades raciais que existem na sociedade brasileira e no mercado de trabalho, representados pela pirâmide hierárquica, em que os negros aparecem na base, em sua maioria as mulheres negras. Vemos também essa hierarquia, na questão salarial, em que o homem branco aparece liderando, seguido da mulher branca, abaixo o homem negro e por último a mulher negra.

De acordo com os marcadores sociais, apresentados no $3^{\circ}$ módulo do livro Políticas Públicas e Raça:

\begin{abstract}
As mulheres que começam a se movimentar para ocupação de nível superior são predominantemente brancas, enquanto que há uma forte concentração de mulheres pretas e pardas no serviço doméstico. As mulheres provenientes das classes mais pobres (majoritariamente negra) se dirigem para a prestação de serviços e para empregos ligados à produção na indústria, enquanto que as mulheres de classe média se dirigem para o serviço de produção e de consumo coletivo (setor terciário) devido aos seus melhores níveis educacionais. (PPR, p.165-166 apud SANTOS et al. 2017 p. s/p)
\end{abstract}

As mulheres brancas ainda têm uma certa vantagem em relação as mulheres negras. Enquanto as mulheres brancas têm maior predominância no nível superior, as mulheres negras, estão mais propensas a realizarem trabalho doméstico. 
Observando a história, podemos ver que as mulheres adquiriram muitos direitos no mundo laboral, direitos esses, adquiridos por meio de muita luta e reivindicações e mesmo assim ainda há muito o que conquistar, como igualdade de gênero, etnia e direitos no mercado de trabalho.

\title{
3.2 Discriminação da mulher no ambiente de trabalho
}

A relação da mulher com o trabalho não pode ser descrita apenas pelo que ela vive na sua função no meio laboral remunerado. Para entender sua realidade, é necessário observar a dupla jornada de trabalho. Além de trabalharem fora de casa, a maior parte da população feminina também exerce trabalho não remunerado em seus lares, como citado anteriormente. O problema é que sem a ajuda masculina para esses afazeres domésticos, as mulheres acabam se sobrecarregando e em algumas vezes acabam deixando seu emprego comprometido, ou deixando de se dedicarem como gostariam ao trabalho.

Juliana Bracks, professora de Direito da Fundação Getúlio Vargas, diz que:

\begin{abstract}
Na nossa sociedade, quando uma família tem filhos, a mulher é quem geralmente falta ao trabalho quando acontece algum problema com as crianças. Os empregadores tradicionais do Brasil ainda pensam dessa forma e isso compromete muita a ascensão social e financeira. No código interno de algumas empresas antigas havia cláusulas dizendo, por exemplo, que uma mulher que "contraísse núpcias" seria demitida. Já tive que analisar um contrato de trabalho que ainda continha essa norma (BRACKS, 2017)
\end{abstract}

Foi mais ou menos isso que aconteceu com Michele Pereira, de 27 anos, que acabou sendo demitida de seu emprego em uma casa de família em que trabalhava como doméstica, após dar à luz a seu primeiro filho. Ela relata que sua patroa ficava nervosa quando em situações corriqueiras e emergenciais como quando seu filho adoecia e ela tinha que faltar (WERNER, 2017).

Existe uma preterição e a discriminação pelas mulheres gestantes, que batem de frente com as normas de proteção da mulher, igualando também o salário por identidade de função.

Não bastando a divisão sexual, que impõe que as mulheres sejam ou se sintam responsáveis pelos afazeres domésticos e pela família, as mulheres ainda têm de se afastar geralmente de seus empregos para cuidar dos filhos, tendo que abandonar suas carreiras sem saber ao certo quando vão voltar, e se vão voltar. E mesmo vivendo em dupla jornada, as mulheres ainda convivem com a desigualdade salarial, já comentada. 
Outro problema que assola a vida laboral das mulheres é o assédio sexual. Como se não fosse o bastante, toda a discriminação trabalhista relacionada ao gênero, as mulheres ainda enfrentam mais essa situação.

Em pesquisa feita pelo Ministério Público do Trabalho (2017, on line), observa-se que o número de denúncias têm aumentado gradativamente nos últimos anos, e é graças ao debate da desigualdade de gênero e assédio que tem fortalecido as mulheres a lutarem e não se envergonharem de correr expor os fatos sofridos.

O assédio sexual é um crime previsto no Código Penal, mas como acontece muitas das vezes no ambiente de trabalho, a Justiça Trabalhista também poderá ser ativada.

Para ser caracterizado assédio sexual, dentro do Direito Penal, o indivíduo superior hierárquico, em busca de vantagem ou favores sexuais, constrange alguém por meio de intimidação ou chantagem, e pode levar punição prevista na lei de detenção de um a dois anos, podendo a pena ser aumentada em um terço se a vítima for menor de dezoito anos.

Já na Justiça do Trabalho não existe necessidade a diferença hierárquica para ser caracterizado o assédio, desde que tenha havido o constrangimento sexual sem o consentimento da mulher, podendo ser cometida por qualquer pessoa do ambiente laboral.

Destarte, importante a luta das mulheres dos atos de discriminação sofridos, além dos casos específicos de assédio sexual.

\subsection{Discriminação da mulher negra no ambiente de trabalho}

A mulher negra no Brasil, diante de um cenário histórico marcado pela escravidão, carrega em sua pele e traços as desvantagens e desigualdades sofridas naquele tempo e que se arrastam até os dias atuais.

A professora do Departamento de Ciências Sociais da Universidade de Londrina, Maria Nilza Silva afirma:

Na atualidade não se pode tratar a questão racial como elemento secundário,
destacando apenas a problemática econômica. A posição social do negro não se
baseia apenas na possibilidade de aquisição ou consumo de bens. Ainda há uma
grande dificuldade da sociedade brasileira em assumir a questão racial como um
problema que necessita ser enfrentado. Enquanto esse processo de enfrentamento
não ocorrer, as desigualdades sociais baseadas na discriminação racial continuarão,
e, com tendência ao acirramento, ainda mais quando se trata de igualdade de
oportunidades em todos os aspectos da sociedade. (SILVA, 2005)

As mulheres negras estão no grupo social que representam o menor nível de ensino e a maior jornada de trabalho, porém, ter a maior jornada de trabalho não significa de modo 
algum neste caso que elas têm o maior rendimento, ao contrário do que seria o lógico, as mulheres negras enfrentam o menor rendimento, ou seja, os menores salários.

O preconceito se inicia desde quando decidem concorrer a uma vaga de emprego, quando são olhadas de uma maneira diferente até mesmo ao distribuir seu currículo nas empresas e ouvem que não estão contratando, e em outros momentos em que é possível notar o racismo. Infelizmente para muitos, essa situação ainda é vista como vitimismo, mas essa é uma triste realidade que assola não só as mulheres, mas toda a classe negra. Para Pinto, essa falta de oportunidade a mulher negra, reflete em suas vidas até quando estiverem em idade mais avançada, pois existem muitas mulheres negras idosas que não possuem o benefício da aposentadoria devido a falta de oportunidade e discriminação ao longo de suas vidas.

\begin{abstract}
$\mathrm{Na}$ desigualdade por gênero e raça, não há novidade sobre o fato das mulheres negras ganharem menos que os homens em todos os estados brasileiros e em todos os níveis de escolaridade. Elas saem do mercado mais tarde, se aposentam em menores proporções que os homens e há mais mulheres negras idosas que não recebem nem aposentadoria nem pensão. Isto reflete as condições em que estas mulheres estão no mercado brasileiro. (PINTO, 2006, p.4).
\end{abstract}

Segundo a Secretária Nacional de Combate ao Racismo da Central Única dos Trabalhadores-CUT, 70\% dos postos de trabalho precarizados são ocupados por negros. Na desigualdade entre negros e brancos, os negros recebem menos que os brancos. E quando se fala de mulher negra, é pior, porque sofre dupla discriminação. (Contraf-CUT, 2015)

De acordo com pesquisa feita pelo IPEA - Instituto de Pesquisa Econômica Aplicada, entre os anos de 1996 e 2003, o aumento nas taxas de desemprego se deu de forma mais acentuada para negros e mulheres do que para a população masculina e branca. (IPEA, 2014, p. 17).

A verdade é que poucas mulheres com essa carga histórica conseguem vencer as barreiras da discriminação, do preconceito e da diferenciação de gêneros e se destacar profissionalmente onde desejam.

O grande desafio, é abrir e preparar o mercado de trabalho para as mulheres, e as mulheres negras, mas para isso é necessário que a sociedade seja ensinada a recebê-las e as tratar com o devido respeito e igualdade.

São diversos os casos de mulheres negras e empoderadas que conseguiram ter prestígio e reconhecimento na sociedade pelo trabalho que prestam. Uma delas é Alexandra Loras, francesa, executiva, e ex-consulesa da França, autora de diversos livros que têm como 
objetivo a equiparação da diversidade étnico-racial. Atua como palestrante em empresas nacionais e internacionais, e já alcançou mais de 20 mil pessoas em todo o mundo com seu discurso, também tem grande destaque por ser atualmente a única mulher negra CEO (diretora executiva) de uma multinacional no país, comandando no Brasil uma marca global de tv africana chamada Trace TV, onde também aborda temas polêmicos e que são velados pela sociedade como a discriminação e o racismo.

Alexandra acredita que o Brasil é país mais racista do mundo,

Viajei por 50 países e vivi em oito deles. O Brasil é o segundo com a maior população de negros, depois da Nigéria. Quando cheguei aqui e liguei a tevê, não vi negros nos desenhos animados, nas novelas, nos telejornais. Nem 54\% em cargos públicos. Somente $4 \%$. O que me fez concluir que se tratava do país mais racista do mundo. (MAGGIO apud LORAS)

Ela ainda provoca nas pessoas um novo pensamento, que se enxerguem do outro lado da situação,

\begin{abstract}
Como seria e como se sentiriam se os livros didáticos só apresentassem personalidades negras? Se na televisão todos os protagonistas fossem negros? Se na novela a mulher branca fosse representada como a faxineira ou com uma imagem hipersexualizada de uma mulher que sempre aparece para acabar com a vida de um casal feliz e saudável? Se o branco fosse sempre o traficante? Seria cruel, não seria? (MAGGIO apud LORAS)
\end{abstract}

A consulesa afirma que mesmo estando em um nível social elevado, ainda sofre preconceito, como por exemplo, ao levar seu filho de pele clara e cabelos loiros em clubes, já foi confundida diversas vezes com a baba da criança, apenas pelo fato de ser negra, ou por exemplo, em cerimônias em que convidados a ignoravam por não imaginarem que ela seria a mulher de um cônsul.

Loras, ainda é a idealizadora de uma plataforma chamada Protagonizo, que conta com a ajuda de empresas multinacionais que apoiaram a ideia. Criado com a função de dar oportunidade e aproximar o público negro ao mercado de trabalho.

Cumpre citar também um caso de racismo contra uma mulher negra no ambiente laboral e que repercutiu nas redes sociais. A advogada Valéria Santos, durante uma audiência no $3^{\circ}$ Juizado Especial Cível de Duque de Caxias, na baixada fluminense, foi algemada e levada para delegacia, após entrar em desacordo com a juíza sobre acesso ao processo de sua cliente.

No momento dos fatos, diversos vídeos foram feitos. Vídeos estes que mostram a discussão entre a advogada e a juíza, momento que Valéria diz ser mulher, negra e advogada, 
e que tem o direito de trabalhar, também o momento em que Valéria pede a presença da OAB para julgar a questão e se nega a sair da sala até a chegada de um representante da Ordem dos Advogados, momento este em que a juíza manda prender a advogada. Em outro vídeo, a advogada aparece no chão, algemada e cercada pelos agentes, sem qualquer defesa, totalmente vulnerável.

Valéria foi levada, para a delegacia, onde só foi liberada após a chegada do representante da Ordem dos Advogados. Luciano Bandeira, presidente da Comissão Estadual de Defesa de Prerrogativas da OAB Rio de Janeiro, defende a postura da advogada, alegando que não houve nenhum erro em sua conduta e que sua prisão foi inadmissível.

O que se questiona é se o fato de Valéria ser negra influenciou. Se ela fosse branca ou um homem branco, o tratamento seria o mesmo? A resposta é que esse questionamento não deveria existir, a igualdade e o respeito entre os gêneros e raças no ambiente profissional e social deveriam ser para todos sem distinção. É aterrorizante testemunhar o descaso que sofrem os negros e as mulheres.

\section{DA PROTEÇÃO A MULHER}

As mulheres conquistaram diversos direitos após muita luta, e direitos adquiridos, em razão da efetivação do Princípio Constitucional da Igualdade, e a partir do Princípio Constitucional da Não Discriminação, que oferece e assegura total efetivação do direito do trabalho em relação ao trabalho da mulher.

\subsection{Princípio Constitucional da Igualdade}

Considerado um dos mais importantes princípios previstos no ordenamento jurídico brasileiro, é previsto na Constituição Federal, como uma cláusula pétrea.

Para Aristóteles, "Devemos tratar igualmente os iguais e desigualmente os desiguais, na medida de sua desigualdade", já a Constituição prevê tratamento igual pela lei a todos indivíduos. Dispõe o artigo $5^{\circ}$, inciso $\mathrm{I}$, da CF, que todos são iguais perante a lei, e não deve haver distinção entre homens e mulheres nos termos da Constituição (BRASIL, on line):

Art. $5^{\circ}$ Todos são iguais perante a lei, sem distinção de qualquer natureza, garantindo-se aos brasileiros e aos estrangeiros residentes no País a inviolabilidade do direito à vida, à liberdade, à igualdade, à segurança e à propriedade, nos termos seguintes: I - homens e mulheres são iguais em direitos e obrigações, nos termos desta Constituição; [...] 
Mas é o artigo $7^{\circ}$ da Constituição Federal (BRASIL, on line), que discorre sobre o princípio da igualdade e sua aplicação no Direito do Trabalho

\footnotetext{
Art. $7^{\circ}$ São direitos dos trabalhadores urbanos e rurais, além de outros que visem à melhoria de sua condição social:

(...)

XXX - proibição de diferença de salários, de exercício de funções e de critério de admissão por motivo de sexo, idade, cor ou estado civil;

XXXI - proibição de qualquer discriminação no tocante a salário e critérios de admissão do trabalhador portador de deficiência;

XXXII - proibição de distinção entre trabalho manual, técnico e intelectual ou entre os profissionais respectivos;

XXXIV - igualdade de direitos entre o trabalhador com vínculo empregatício permanente e o trabalhador avulso.
}

Já o artigo $5^{\circ}$ da CLT (on line), fala em seu texto "A todo trabalho de igual valor corresponderá salário igual, sem distinção de sexo".

No mercado de trabalho, ocorre violação do princípio da igualdade, visto que mesmo com as leis, ainda existem discrepâncias como por exemplo, na distribuição dos salários para trabalhos de igual valor.

A igualdade pode ser formal, ou material. Compreende-se como igualdade formal, o tratamento sem diferenciações, independentemente da situação. E a igualdade material, como a compreensão do agente e suas individualidades, respeitando suas características.

\subsection{Princípio Constitucional da Não Discriminação}

O Princípio da Não Discriminação, tem como principal objetivo, proibir todo e qualquer tipo de discriminação injustificada, que possam existir nas relações de trabalho.

Discriminação é a conduta pela qual se nega a alguém tratamento compatível com a situação concreta vivenciada, de acordo com o padrão jurídico assentado, onde o princípio da não-discriminação, nega validade a essa conduta discriminatória. (DELGADO, 2001, p. 122)

Esse princípio, exclui qualquer diferenciação que trate o trabalhador de maneira inferior ou desigual ao coletivo, sem motivo algum ou apoio legal.

Para Mauricio Godinho Delgado:

O princípio da não-discriminação é princípio de proteção, de resistência, denegatório de conduta que se considera gravemente censurável. Portanto, labora sobre um piso de civilidade que se considera mínimo para a convivência entre as pessoas. (2001, p. 122)

Um exemplo do emprego deste princípio dentro do Direito do Trabalho, é o impedimento de tratamento diferente entre o empregado e uma empregada, contratados com 
mesma função e exercendo o mesmo trabalho com igual valor, pelo fato da empregada sem mulher. $\mathrm{O}$ ordenamento jurídico não admite essa maneira de diferenciação atuar nas relações de trabalho, apoiando o respeito e a equiparação dentro do ambiente de trabalho.

\section{CONCLUSÃO}

É necessário o rompimento dos padrões impostos por parte da sociedade, e perceber a necessidade da busca pela ascensão e equiparação de oportunidades dentro do mercado de trabalho, entre homens e mulheres.

Somente a igualdade jurídica, que é prevista nas leis, não é o suficiente para mudar o entendimento discriminatório adotado pela sociedade. É necessário a conscientização da importância da inclusão de todos na sociedade, independente de serem eles homens e mulheres, negros ou brancos, sem distinção de gênero, raça, nacionalidade, cor, sexo, etnia, orientação sexual ou religião e compreendam que todos somos diferentes, e é isso que nos tornam únicos, cada um a sua maneira, é imprescindível que o ser humano aprenda a respeitar e a conviver com as diferenças do outro.

Com uma carga histórica repleta de discriminação e desigualdade, a mulher sofre com esses fatores que marcaram sua trajetória e têm reflexos ainda hoje em sua vida profissional e pessoal.

O intuito do presente trabalho foi analisar a discriminação sofrida pelas mulheres no ambiente de trabalho, sobretudo a mulher negra.

A discriminação no mercado de trabalho ocorre tanto por parte dos empregadores como por parte dos colegas de trabalho. Os empregadores, muitas das vezes, desvalorizam o trabalho da mulher por duvidarem de sua capacidade para realizarem algum tipo de função, dando preferência aos homens, o que faz até mesmo algumas mulheres acabarem aceitando o papel de inferiorização que lhes é condicionado. Já a discriminação por parte dos colegas de trabalho ocorre com grande frequência, como a recusa de algum funcionário em trabalhar com uma mulher, por ser ela mulher, ou ainda, mulher e negra.

As mulheres se deparam com uma maior dificuldade de encontrar empregos e mais ainda de se manterem neles. Além do trabalho no ambiente laboral, a mulher ainda conta com o trabalho doméstico, as chamadas duplas jornadas, o que acaba deixando prejuízos ou no ambiente profissional ou no ambiente pessoal. 
A parcela mais pobre da sociedade, no Brasil, é formada por mulheres negras, e no ambiente de trabalho, elas possuem o menor salário, abaixo das mulheres brancas, possuem as piores condições de trabalho e ainda estão na frente liderando as porcentagens do desemprego e recebendo os menores salários. Elas ainda ocupam os cargos inferiores e mais desvalorizados, pois não possuem alta qualificação profissional e além disso, por falta de instrução e ensino.

Além da discriminação por gênero sofrido pelas mulheres, as mulheres negras ainda carregam o peso do racismo, que se faz presente e constante em seu dia a dia.

Nossos representantes devem providenciar a elaboração de políticas destinadas a criar novas oportunidades de trabalho e combater a discriminação, entre os gêneros e raças.

Um longo caminho cultural, social e político deverá ser percorrido para que finalmente a equiparação entre homem, mulher e negros seja notória, e reconhecida por todos.

\section{REFERÊNCIAS}

BRASIL. Constituição da República Federativa do Brasil. Disponível em: http://www.planalto.gov.br/ccivil_03/constituicao/constituicao.htm. Acesso em: 02 fev. 2019.

CATHO - FERRAZ, Eduardo. As diferenças entre homens e mulheres no mercado de trabalho. 2017. Disponível em <https://www.catho.com.br/carreirasucesso/colunistas/eduardo-ferraz/as-diferencas-entre-homens-e-mulheres-no-mercado-detrabalho/>. Acesso em: 26 mar. 2019.

CISNE, Mirla. Gênero. Divisão Sexual do Trabalho e Serviço Social. $2^{\mathrm{a}}$ ed. São Paulo: Outras Expressões, 2015.

CLT - Consolidação das Leis Trabalhistas. Decreto-Lei $\mathrm{n}^{\circ} 5.452$, de $1^{\circ}$ de maio de 1943. Disponível em: http://www.planalto.gov.br/ccivil_03/decreto-lei/del5452.htm. Acesso em: 04 fev. 2019.

CONFEDERAÇÃO NACIONAL DOS TRABALHADORES DO RAMO FINANCEIRO DA CUT. Confracut: Mulheres negras enfrentam discriminação, racismo ainda persiste no trabalho. 2015. Disponível em: <http://www.contrafcut.org.br/noticias/mulheres-negrasenfrentam-discriminacao-racismo-ainda-persiste-no-trabalho-d6bf $>$. Acesso em: 01 mar. 2019.

DELGADO, Mauricio Godinho. Princípios de Direito Individual e Coletivo do Trabalho. São Paulo: LTr, 2001.

GOSDAL, Thereza Cristina. Discriminação da Mulher no Emprego. Curitiba: Genesis, 2003. 
IBGE - Instituto Brasileiro de Geografia e Estatística - Pesquisa Nacional por Amostra de Domicílios Contínua (PNAD). Disponível em: <https://educa.ibge.gov.br/jovens/conheca-obrasil/populacao/18320-quantidade-de-homens-e-mulheres.html>. Acesso em: 30 mar. 2019.

IPEA - Instituto de Pesquisa Econômica Aplicada. Secretaria de Políticas de Promoção da Igualdade Racial - SEPPIR. Situação social da população negra por estado. Brasília, 2014.

LAURETIS, Teresa de. A tecnologia do gênero. In: HOLLANDA, Heloísa Buarque de. (Org.). Tendências e impasses: o feminismo como crítica da Cultura. Rio de Janeiro: Rocco, 1994.

MAGGIO, Sergio. Metrópoles: Quem é Alexandra Loras? A francesa que faz o Brasil repensar o racismo. 2017. Disponível em: <https://www.metropoles.com/colunas-blogs/tipoassim/quem-e-alexandra-loras-a-francesa-que-faz-o-brasil-repensar-o-racismo > Acesso em: 02 abr. 2019.

MPT - Ministério Público do Trabalho. Cartilha Assédio Moral. Disponível em: <http://www.mpf.mp.br/sc/arquivos/cartilha-assedio>. Acesso em: 03 jun. 2019.

NOGUEIRA, Claudia Mazzei. As relações sociais de gênero no trabalho e na reprodução. Revista Aurora, São Paulo, n. 6, p. 59-62, ago. 2010. Disponível em: http://www.marilia.unesp.br/Home/RevistasEletronicas/Aurora/6\%20NOGUEIRA,\%20Claud ia\%20Mazzei.pdf>. Acesso em: 25 jan. 2019.

NYE, Andréa. Teoria feminista e as filosofias do homem. Rio de Janeiro: Rosa dos Tempos, 1995.

ORGANIZAÇÃO INTERNACIONAL DO TRABALHO. OIT: As mulheres ainda são menos propensas que os homens a participar do mercado de trabalho em grande parte do mundo. 2018. Disponível em <https://www.ilo.org/global/about-theilo/newsroom/news/WCMS_619550?lang=es> Acesso em: 29 abr. 2019.

PINTO, Giselle. Situação das mulheres negras no mercado de trabalho: uma análise dos indicadores sociais. Trabalho apresentado no XIV Encontro Nacional de Estudos Populacionais, ABEP, realizado em Caxambú (MG), de 18-22 set. 2006. Disponível em: http://files.ufgd.edu.br/arquivos/arquivos/78/NEAB/Giselle\%20Pinto.PDF. Acesso em: 01 mai. 2019.

SANTOS, M. S dos.; QUEIROZ, J. M de.; LUZ, R. A da; OLIVEIRA, S. B. Desigualdades de gênero: a mulher negra no mercado de trabalho, In: VIII jornada internacional de políticas públicas. 2017.Disponível em:

<http://www.joinpp.ufma.br/jornadas/joinpp2017/pdfs/eixo6/desigualdadesdegeneroamulhern egranomercadodetrabalho.pdf>. Acesso em: 01 abr. 2019.

SILVA, Maria Nilza da. A Mulher Negra. 2005 Disponível em: <www.espacoacademico.com.br> Acesso em: 01 mai. 2019. 
WERNER, Luciana, participação de BRACKS Juliana. "Projeto Colabora: Discriminação contra a mulher no trabalho persiste" 2017 Disponível em:

<https://projetocolabora.com.br/inclusao-social/discriminacao-contra-a-mulher-persiste/>, Acesso em: 01 abr. 2019. 